\title{
Consumer Perception on Organic Products: A Study on the Select Products of Patanjali Ayurveda Limited
}

\author{
Dr. V. Krishnamohan ${ }^{1}$, Ch.S.S.S.Kumar ${ }^{2}$ \\ ${ }^{1}$ Professor, Dept of Commerce and Management Studies (DCMS), Andhra University, \\ Visakhapatnam (AP) 530003. \\ ${ }^{2}$ Asst Professor, Dept of Management Studies, Gayatri Vidya Parishad, College of Engineering (Autonomous), \\ Madhurawada, Visakhapatnam (AP) -530048.
}

\section{Introduction}

The modern world is witnessing a wide spread expansion in the usage of organic products, be it food products, personal \& health-care products and cosmetics for the varied and valid reasons. Organic products are becoming more popular and people choose them for distinct advantages. The terms herbal, ayurvedic, natural and organic are not only distinct in their properties but also functionally have a variance in the applications.

\subsection{Statement of Problem}

Consequent to the onset of technology the consumers have become more aware of what they exactly need and find it easy to access the required information on the products they require and their tastes and preferences are changing with the trends and are inclined towards the luxuries of life within their available resources. The changing face of consumerism has become a boon as well as a bane for the manufacturers and it is turning to be a challenging task for them in meeting the expectations of the modern consumers to their satisfactory levels. This tendency is prevalent more in organic products market with the changing patterns of consumer behavior.

\subsection{Research Questions}

i) What is the existing scenario of organic products globally in general and domestic in particular?

ii) What are the consumers' intentions, perceptions, attitudes, beliefs and expectations towards Patanjali Organic products?

\subsection{Objective}

The research objective is to examine the consumer perception and its influence in the consumption of organic products in general and select offerings of Patanjali Ayurveda Limited.

\subsection{Formulation of Hypotheses}

The study has given a pedestal for framing an objective \& outcome oriented and testable hypothesis for analogous to the undertaken research. The empirical research conducted through the meticulous data collection and analysis has been assimilated through demographic factors as described hereunder.

$\mathbf{H}_{1}$ : Demographic factors such as Age, Gender, Income, Education, Occupation and Family Income have a significant influence on the perception of consumers and their behavior in buying Patanjali Organic products

\subsection{Research Methodology}

Research is the systematic investigation into and study of materials and sources in order to establish facts and reach new set of relations and draw meaningful conclusions. The methodology is the systematic, theoretical analysis of the methods applied to a field of study, which comprises the theoretical analysis of the body of methods and principles associated with a branch of knowledge. Typically, it encompasses concepts such as paradigm, theoretical model, phases and quantitative and/or qualitative techniques. The current research is descriptive in nature and adopted both qualitative and quantitative methodologies in a panoramic angle addressing several intricate factors. 


\subsubsection{Sources of Data}

Both Primary and Secondary data have been collected by physically visiting 50 Patanjali outlets and 20 general Organic outlets in Visakhapatnam City and obtained responses from 650 participants out of which 475 responses including 145 personal interview responses are taken into consideration for data analysis. Primary data collection has been made by adopting two popular methods i.e. questionnaire and interview method. Secondary data has been collected from research papers, conference reports, online journals, business magazines, newspapers, annual reports, etc.

\subsubsection{Sampling Design}

The study has considered non-profitability sampling method. The sampling technique and subsequent selection of the total population size and related subsets, to suit the situation in the current research have been processed to finalize the sample size.

\subsubsection{Sample Size}

The survey was conducted in three stages. The $1^{\text {st }}$ round was done among 100 respondents, the $2^{\text {nd }}$ round among 200 respondents and $3^{\text {rd }}$ round among 650 participants. The following formula has been used for data analysis:

\subsubsection{Statistical tools used}

$$
\text { Sample Size }=\frac{\frac{z^{2} \times p(1-p)}{e^{2}}}{1+\left(\frac{z^{2} \times p(1-p)}{e^{2} N}\right)}
$$

This research by its high magnitude and scope has a need to adopt both qualitative and quantitative approaches. As necessitated the result for each type of variable in respect of qualitative data presented as frequencies and percentages. In case of quantitative variables the presentation is as means and deviations. The process of analysis calls for the application of several statistical test methods in order to arrive at justifying the hypotheses. Because of the complexity involved in the whole process one way ANOVA test has been applied since it is used to determine whether there are any statistically significant differences between the means of three or more independent (unrelated) groups.

\subsubsection{Scope of the Study}

The current study involves the analysis of the changing face of the consumer dynamics and the dynamics of change in the happenings of the organic product markets. The organic products, by virtue of their minimum side effects in all categories including food, personal care products, cosmetics and medicines people generally get attracted towards them. When there were ups and downs in the organic product markets the Patanjali products have surged and dominated both in the aspects of revenues and customers following. The trend has been indicating an exponential growth until 2018 and the graph has been slanted due to several explicit and implicit reasons. The fall in customer base needs a special investigation in the changing movements of consumer behaviour in terms of the attitudinal aspects, motivational factors, beliefs, expectations, aspirations, perceptions, intentions and levels of satisfaction with another most important element the 'trust'.

2.1 Consumer Demographics: A sample size of 475 has been considered for data analysis.

Table 2.1: Consumer Demographics

\begin{tabular}{|l|l|l|l|l|l|l|l|}
\hline \multirow{2}{*}{ Demographics } & \multirow{2}{*}{ Age Groups } & \multicolumn{3}{|l|}{ Gender } & \multirow{2}{*}{ Total } & \multirow{2}{*}{$(\boldsymbol{\%})$} \\
\cline { 3 - 9 } & & Male & $\mathbf{( \% )}$ & Female & $\mathbf{( \% )}$ & & \\
\hline \multirow{4}{*}{ Age } & Below 25 & 40 & 8.42 & 20 & 4.21 & 60 & 12.63 \\
\cline { 2 - 9 } & 26-35 Years & 70 & 14.74 & 35 & 7.37 & 105 & 22.11 \\
\cline { 2 - 8 } & 36-45 Years & 80 & 16.84 & 40 & 8.42 & 120 & 25.26 \\
\cline { 2 - 8 } & 46-55 Years & 70 & 14.74 & 35 & 7.37 & 105 & 22.11 \\
\cline { 2 - 8 } & Above 55 Years & 60 & 12.63 & 25 & 5.26 & 85 & 17.89 \\
\hline
\end{tabular}




\begin{tabular}{|c|c|c|c|c|c|c|c|}
\hline \multicolumn{2}{|c|}{ Total } & 320 & 67.37 & 155 & 32.63 & 475 & 100.00 \\
\hline \multirow{6}{*}{ Education } & $10^{\text {th }}$ & 15 & 3.16 & 5 & 1.05 & 20 & 4.21 \\
\hline & Inter & 20 & 4.21 & 10 & 2.11 & 30 & 6.32 \\
\hline & Graduate & 115 & 24.21 & 55 & 11.58 & 170 & 35.79 \\
\hline & Post Graduate & 105 & 22.11 & 50 & 10.53 & 155 & 32.63 \\
\hline & Professional Courses & 35 & 7.37 & 20 & 4.21 & 55 & 11.58 \\
\hline & Others & 30 & 6.32 & 15 & 3.16 & 45 & 9.47 \\
\hline \multicolumn{2}{|l|}{ Total } & 320 & 67.37 & 155 & 32.63 & 475 & 100.00 \\
\hline \multirow{6}{*}{ Occupation } & Govt. Employee & 90 & 18.95 & 20 & 4.21 & 110 & 23.16 \\
\hline & Private Employee & 120 & 25.26 & 40 & 8.42 & 160 & 33.68 \\
\hline & Professional & 35 & 7.37 & 20 & 4.21 & 55 & 11.58 \\
\hline & Business & 60 & 12.63 & 25 & 5.26 & 85 & 17.89 \\
\hline & Home Maker & 0 & 0.00 & 50 & 10.53 & 50 & 10.53 \\
\hline & Student & 15 & 3.16 & 0 & 0.00 & 15 & 3.16 \\
\hline \multicolumn{2}{|l|}{ Total } & 320 & 67.37 & 155 & 32.63 & 475 & 100.00 \\
\hline \multirow{3}{*}{ Marital Status } & Single & 35 & 7.37 & 20 & 4.21 & 55 & 11.58 \\
\hline & Married & 285 & 60.00 & 120 & 25.26 & 405 & 85.26 \\
\hline & Divorced/Widowed & 0 & 0.00 & 15 & 3.16 & 15 & 3.16 \\
\hline \multicolumn{2}{|l|}{ Total } & 320 & 67.37 & 155 & 32.63 & 475 & 100.00 \\
\hline \multirow{6}{*}{ Family Size } & Single & 4 & 0.84 & 1 & 0.21 & 5 & 1.05 \\
\hline & Two & 75 & 15.79 & 40 & 8.42 & 115 & 24.21 \\
\hline & Three & 118 & 24.84 & 67 & 14.11 & 185 & 38.95 \\
\hline & Four & 78 & 16.42 & 37 & 7.79 & 115 & 24.21 \\
\hline & Five & 10 & 2.11 & 5 & 1.05 & 15 & 3.16 \\
\hline & Above Five & 35 & 7.37 & 5 & 1.05 & 40 & 8.42 \\
\hline \multicolumn{2}{|l|}{ Total } & 320 & 67.37 & 155 & 32.63 & 475 & 100.00 \\
\hline \multirow{6}{*}{ Income } & Dependent & 15 & 3.16 & 45 & 9.47 & 60 & 12.63 \\
\hline & Below ₹10,000 & 35 & 7.37 & 0 & 0.00 & 35 & 7.37 \\
\hline & ₹10,001-₹25,000 & 35 & 7.37 & 40 & 8.42 & 75 & 15.79 \\
\hline & ₹25,001-₹50,000 & 145 & 30.53 & 51 & 10.74 & 200 & 42.11 \\
\hline & ₹50,001-₹1,00,000 & 74 & 15.58 & 15 & 3.16 & 85 & 17.89 \\
\hline & Above ₹ $1,00,000$ & 16 & 3.37 & 4 & 0.84 & 20 & 4.21 \\
\hline \multicolumn{2}{|l|}{ Total } & 320 & 67.37 & 155 & 32.63 & 475 & 100.00 \\
\hline \multirow{4}{*}{ Family Income } & ₹10,001-₹25,000 & 19 & 5.94 & 8 & 5.16 & 27 & 5.68 \\
\hline & ₹ $25,001-₹ 50,000$ & 32 & 10.00 & 3 & 1.94 & 35 & 7.37 \\
\hline & ₹ 50,001-₹ $1,00,000$ & 24 & 7.50 & 2 & 1.29 & 26 & 5.47 \\
\hline & Above ₹1,00,000 & 0 & 0 & 0 & 0 & 0 & 0 \\
\hline \multicolumn{2}{|l|}{ Total } & 75 & 23.44 & 13 & 8.39 & 88 & 18.53 \\
\hline \multirow{3}{*}{ Residence } & Rural & 15 & 3.16 & 5 & 1.05 & 20 & 4.21 \\
\hline & Urban & 225 & 47.37 & 105 & 22.11 & 330 & 69.47 \\
\hline & Semi-Urban & 80 & 16.84 & 45 & 9.47 & 125 & 26.32 \\
\hline \multicolumn{2}{|l|}{ Total } & 320 & 67.37 & 155 & 32.63 & 475 & 100.00 \\
\hline
\end{tabular}


Table 2.1 shows that out of 475 respondents:

i) $\quad 320$ respondents i.e. 67.37 percent are males and remaining 155 respondents i.e. 32.63 percent are females.

ii) Respondents falling below the age of 25 are 60 i.e. 12.63 percent out of which 40 are males i.e. 8.42 percent and remaining 20 are females i.e. 4.21 percent. Respondents falling between the ages 26-35 are 105 i.e. 22.11 percent in number out of which 70 are males i.e. 14.74 percent and the remaining 35 are females i.e. 7.37 percent. Respondents falling between the ages $36-45$ are 120 i.e. 25.26 percent in number out of which 80 are males i.e. 16.84 percent and the remaining 40are females i.e. 8.42 percent. Respondents falling between the ages $46-55$ are 105 i.e. 22.11 percent in number out of which 70 are males i.e. 14.74 percent and the remaining 35 are females i.e. 7.37 percent. Respondents above the age 55 are 85 in number i.e. 17.89 percent out of which 60 are males i.e. 12.63 percent and the remaining 25 are females i.e. 5.26percent.

iii) Customers possessing educational qualification not beyond $10^{\text {th }}$ Standard are 20 in number i.e. 4.21 percent out of which 15 i.e. 3.16 percent are males and remaining 5 are females i.e. 1.05 percent. Respondents who have Intermediate pass-out are 30 in number i.e. 6.32 percent out of which 20 are males i.e. 4.21 percent and the remaining 10 are females i.e. 2.11 percent. Customers who are graduates are 170 in number i.e. 35.79 percent out of which 115 are males i.e. 24.21 percent and the remaining 55 are females i.e. 11.58 percent. Respondents who are post graduates are 155 in number out of which 105 are males i.e. 22.11 percent and the remaining are 50 are females i.e. 10.53 percent. Customers with professional qualification are 55 in number i.e. 11.58 percent out of which 35 are males i.e. 7.37 percent and the remaining 20 are females i.e. 4.21 percent. Respondents with Diploma, Certificate course, ITI etc are 45 in number i.e. 9. 47 percent out of which 30 are males i.e. 6.32 percent and the remaining 15 are females i.e. 3.16 percent

iv) Respondents who are Government Job Holders are 110 in number i.e. 23.16 percent out of which 90 are males i.e. 18.95 percent and the remaining 20 are females i.e. 4.21 percent. Respondents who are privately employed are 160 in number i.e. 33.68 percent out of which 120 are males i.e. 25.26 percent and the remaining 40 are females i.e. 8.42 percent. Respondents who are practicing professionals like CA's, Doctors, Engineers, Advocates are 55 in number i.e. 11.58 percent out of which 35 are males i.e. 7.37 percent and the remaining 20 are females i.e. 4.21 percent. Respondents who have their own business are 85 in number i.e. 17.89 percent out of which 60 are males i.e. 12.63 percent and the remaining 25 are females i.e. 5.26 percent. Respondents who are homemakers are 50 in number i.e. 10.53 percent Respondents who are male students are 15 in number i.e. 3.16 percent. 55 respondents i.e. 11.58 percent are un-married out of which 35 are males i.e. 7.37 percent and remaining 20 are females i.e. 4.21 percent. 405 respondents are married i.e. 85.26 percent out of which 285 are males i.e. 60percent and the remaining 120 are females i.e. 25.26 percent. 15 respondent females are divorced or widowed i.e. 3.16 percent.

v) Respondents who do not have any family are 5 in number i.e. 1.05 percent out of which 4 i.e. 0.84 percent are males and 1 is a female i.e. 0.21 percent. Respondents with family size 2 are 115 in number i.e. 24.21 percent out of which 75 i.e. 15.79 percent are males and 40 are females i.e. 8.42 percent. Respondents with family size 3 are 185 in number i.e. 38.95 percent out of which 118 i.e. 24.84 percent are males and 67 are females i.e. 14.11 percent. Respondents with family size 4 are 115 in number i.e. 24.21 percent out of which 78 i.e. 16.742 percent are males and 37 are females i.e. 7.79 percent. Respondents with family size 5 are 15 in number i.e. 3.16 percent out of which 10 i.e. 2.11 percent are males and 5 are females i.e. 1.05 percent. Respondents with family size 6 and above are 40 in number i.e. 8.42 percent out of which 35 i.e. 7.37 percent are males and 5 are females i.e. 1.05 percent.

vi) Respondents who have no income are 60 in number i.e. 12.63 percent out of which 15 are males i.e. 3.16 percent and the remaining 45 are females i.e. 9.47 percent. Respondents with an income below Rs 10,000 are 35 in numbers i.e. 7.37 percent are males. Respondents who have income between Rs 10,001 and 25,000 are 75 in number i.e. 15.79 percent out of which 35 are males i.e. 7.37 percent and the remaining 40 are females i.e. 8.42 percent. Respondents who have income 
between Rs 25,001 and 50,000 are 200 in number i.e. 42.11 percent out of which 145 are males i.e. 30.53 percent and the remaining 51 are females i.e. 10.74 percent. Respondents who have income between Rs 50,001 and 1,00,000 are 85 in number i.e. 17.89 percent out of which 74 are males i.e. 15.58 percent and the remaining 15 are females i.e. 3.16 percent. Respondents who have income above Rs 1lakh are 20 in number i.e. 16 percent out of which 16 are males i.e. 3.37 percent and the remaining 4 are females i.e. 0.84 percent.

vii) Respondents whose total family income is in between Rs 10,001 and 25,000 are 27 in number i.e. 5.68 percent out of which 19 are males i.e. 5.94 percent and the remaining 8 are females i.e. 5.16 percent. Respondents whose total family income is in between Rs 25,001 and 50,000 are 35 in number i.e. 7.37 percent out of which 32 are males i.e. 10 percent and the remaining 3 are females i.e. 1.94 percent. Respondents whose total family income is in between Rs 50,001 and 1,00,000 are 26 in number i.e. 5.47 percent out of which 24 are males i.e. 7.5 percent and the remaining 2 are females i.e. 1.29 percent.

viii) Respondents living in rural area are 88 in number i.e. 18.53 percent out of which 75 are males i.e. 23.44 percent and remaining 13 are females i.e. 8.39 percent. Respondents living in urban area are 330 in number i.e. 69.47 percent out of which 225 are males i.e. 47.37 percent and remaining 105 are females i.e. 22.11 percent. Respondents living in semi-urban area are 88 in number i.e. 18.53 percent out of which 75 are males i.e. 23.44 percent and remaining 13 are females i.e. 8.39 percent.

\subsection{Testing of Hypothesis}

Table 2.2: Testing of hypothesis pertaining to Consumer Demographics

\begin{tabular}{|c|c|c|c|c|c|c|}
\hline \multicolumn{7}{|l|}{ ANOVA } \\
\hline & & \begin{tabular}{|l|}
$\begin{array}{l}\text { Sum of } \\
\text { Squares }\end{array}$ \\
\end{tabular} & df & $\begin{array}{l}\text { Mean } \\
\text { Square }\end{array}$ & $\mathbf{F}$ & Sig. \\
\hline \multirow[t]{3}{*}{ Gender } & Between Groups & .005 & 1 & .005 & \multirow{3}{*}{.025} & \multirow{3}{*}{.875} \\
\hline & Within Groups & 104.416 & 473 & .221 & & \\
\hline & Total & 104.421 & 474 & & & \\
\hline \multirow[t]{3}{*}{ Age } & Between Groups & 17.302 & 1 & 17.302 & \multirow{3}{*}{10.664} & \multirow{3}{*}{.001} \\
\hline & Within Groups & 767.435 & 473 & 1.622 & & \\
\hline & Total & 784.737 & 474 & & & \\
\hline \multirow[t]{3}{*}{ Education } & Between Groups & 45.365 & 1 & 45.365 & \multirow{3}{*}{34.870} & \multirow{3}{*}{.000} \\
\hline & Within Groups & 615.372 & 473 & 1.301 & & \\
\hline & Total & 660.737 & 474 & & & \\
\hline \multirow[t]{3}{*}{ Occupation } & Between Groups & 73.898 & 1 & 73.898 & \multirow{3}{*}{38.892} & \multirow{3}{*}{.000} \\
\hline & Within Groups & 898.734 & 473 & 1.900 & & \\
\hline & Total & 972.632 & 474 & & & \\
\hline \multirow[t]{3}{*}{ Marital Status } & Between Groups & .080 & 1 & .080 & \multirow{3}{*}{.571} & \multirow{3}{*}{.450} \\
\hline & Within Groups & 66.551 & 473 & .141 & & \\
\hline & Total & 66.632 & 474 & & & \\
\hline \multirow[t]{3}{*}{ Family Size } & Between Groups & .984 & 1 & .984 & \multirow{3}{*}{.742} & \multirow{3}{*}{.390} \\
\hline & Within Groups & 627.753 & 473 & 1.327 & & \\
\hline & Total & 628.737 & 474 & & & \\
\hline \multirow[t]{3}{*}{ Income } & Between Groups & 187.994 & 1 & 187.994 & \multirow{3}{*}{137.267} & \multirow{3}{*}{.000} \\
\hline & Within Groups & 647.796 & 473 & 1.370 & & \\
\hline & Total & 835.789 & 474 & & & \\
\hline \multirow[t]{3}{*}{ Living Area } & Between Groups & .357 & 1 & .357 & \multirow{3}{*}{1.392} & \multirow{3}{*}{.239} \\
\hline & Within Groups & 121.432 & 473 & .257 & & \\
\hline & Total & 121.789 & 474 & & & \\
\hline
\end{tabular}




\section{The Table 2.2 shows:}

i) The Gender of the respondents, where the $\mathrm{p}>0.05(0.875)$ and $\mathrm{F}=.025$ which means gender has no significant influence on the intention to buy Patanjali products. Hence, the formulated hypothesis "Gender has a significant influence on the intentions of buying Patanjali Organic products" is rejected.

ii) Age of the respondents, where the $\mathrm{p}<0.05(0.001)$ and $\mathrm{F}=10.664$ implies that the age of the respondents has a significant influence on the intention to purchase Patanjali Organic products. Therefore, the formulated hypothesis "Age has a significant influence on the intentions of buying Patanjali Organic products" is accepted.

iii) Education levels of the respondents, where the values of $\mathrm{p}<0.05(0.000)$ and $\mathrm{F}=34.872$ reflect that the consumers' education levels have significant influence on the buying intentions of Patanjali Organic products. It is therefore clear that the formulated hypothesis "Education Levels have significant influence on the intentions of buying Patanjali Organic products" is accepted.

iv) Occupations of the respondents, where the value of $\mathrm{p}<0.05(0.000)$ and $\mathrm{F}=38.892$ clearly indicate that the occupations of the consumers' have significant influence on intentions of purchasing Patanjali Organic products. As such, the formulated hypothesis "Occupations have significant influence on the intentions of buying Patanjali Organic products" is accepted.

v) Marital Status of the respondents, where the value of $p>0.05(0.450)$ and $F=0.571$ can be visualized that the marital status of the consumers have no significant influence on buying interests of Patanjali products. It can therefore be affirmed that the formulated hypothesis "Marital Status have significant influence on the intentions of buying Patanjali Organic products" is rejected.

vi) The Family size of the respondents, where the $p>0.05(0.390)$ and $F=0.742$ ascertains that the consumers' family size does not influence the intentions of purchasing Patanjali organic products. Hence, it can be concluded that the formulated hypothesis "Family Size have significant influence on the intentions of buying Patanjali Organic products" is rejected.

vii) The levels of income of the respondents, where the $\mathrm{p}<0.05(0.000)$ and $\mathrm{F}=137.267$ visualizes that the consumers income level have no bearing on purchasing intentions of Patanjali organic products. It can be arrived-at that the formulated hypothesis "Income has a significant influence on the intentions of buying Patanjali Organic products" is accepted.

viii) The area of inhabitance of the respondents, where $p>0.05(0.239)$ and $F=1.392$ substantiates that the living area of consumers does not matter in purchasing intentions of Patanjali organic products. So, it can be established that the formulated hypothesis "Living Place has a significant influence on the intentions of buying Patanjali Organic products" is rejected.

\subsection{Findings based on Customer's Survey}

i) The study reveals that 435 (95.60 per cent) respondents prefer organic products to general products. Regarding brands of organic products the consumers buy, it is found from the analysis that as many as 385 (84.62 per cent) purchase Patanjali products followed by 260 (57.14 per cent) Dabur, 180 (39.56 per cent) Himalaya, 165 (36.26 per cent) Colgate Palmolive and 105 (23.08 per cent) buy Zandu.

ii) Concerning frequency of purchases, it can be seen from the analysis that 165 (36.26 per cent) purchase once in a month followed by 155 (34.07 percent) twice in a month and 105 (23.08 per cent) purchase once in three months.

iii) The analysis reveals that 400 (87.91 percent) respondents have come to know about the organic products through their friends and relatives, 390 (85.71 percent) via electronic media, 280 (61.54 percent) refer print media and 130 (28.57 percent) depend on internet media.

iv) The study reports that 385 (84.62 per cent) out of 455 organic product users purchase their organic 
products from Patanjali.

v) With reference to their frequency of purchase, it has shown that 180 (46.76 per cent) users of Patanjali products purchase once in month, 125 (32.47 per cent) twice in a month and the rest 80 (20.77 per cent) were purchasing once in two months.

vi) It is identified that 280 (72.73 per cent) Patanjali product users are influenced by the factors like competitive price, followed by 275 (71.43 per cent) for better quality, 280 (72.73 per cent) considered safety, 280 (72.73 per cent) consider health related aspects, 290 (75.32 per cent) depend on brand image, 185 (58.85 per cent) were influenced by the advertisements and 235 (60.04 per cent) consider Baba Ramdev image in their selection of organic products.

\subsection{Suggestions of the Customer}

i) As the pollution levels in the air as well as water contamination, high use of chemicals \& fertilizers are on the rise, hence it is advisable to consume foods with less toxicity levels in order to improve health, fitness and well-being.

ii) All the consumers are suggested to have a broad spectrum of understanding on Organic/Natural products, their functioning as to how they control human metabolism.

iii) In the busy world, the consumers need to find sufficient time to go through the advantages of the Organic, Ayurvedic and Natural products, be it food, personal care, health care, home care products and try to choose their options according to their needs.

iv) While the consumers are generally being influenced by their family, friends, peer groups etc., for using any product or adopting life styles, it is suggested that they should have their own analysis and use their jurisprudence in selecting what exactly they need and what things to avoid. Since this is an easy practice, the consumers are to be specific about the adoption and this also helps them to educate others.

v) The consumers are suggested to exercise caution with respect to the application and suitability while buying health care and personal care products. It is advisable that they go through the ingredients of the products and their side effects, contra indications etc., rather for every product be it Ayurvedic, allopathic or homeopathic. Since in this context the focus is on Ayurvedic medicines or organic health/personal care products, it is better for the consumers to adopt the same practice despite the organic products have their minimum side effects.

vi) Although the brand loyalty spells class and speaks of one's unique identity, it is true in most of the cases like clothing, electrical and electronics items, fashion, perfumes, etc., but in case of the organic products it is in variance depending on the application, suitability and situation. As such the consumers are advised not go more with the brand in organic products because different products have different merits and demerits.

vii) When consumers are tending towards using organic products it is always suggested that they need not compromise with other products due to flimsy reasons like non-availability of products at one particular store but to have enough patience to search for the required organic products. This suggestion is fully in the interest of the consumers' welfare considering no or minimum side effects of organic products, lest the very purpose of going for organic products is defeated.

viii) The organic products, of course, are more expensive than the general products, but in the real sense they outweigh the advantages vis-à-vis the health aspect and the relative expenditure towards medicines in keeping up good health. It is therefore suggestible to prefer organic products only.

ix) It is suggested that the consumers need to maintain loyalty with the retailers and dealers in order to gain more information on the products and periodic updates so that the stores can offer appropriate promotional discounts to retain potential and loyal customers. 
x) Consumers are suggested not to get carried away by the classy advertisements of the MNC's like Colgate-active-salt and other similar advertisements but go with the genuine merits of the product. In this context, it is to say that the Patanjali advertisements may not be so attractive, but conceptually rich and valid with respect to the product benefits.

\section{Bibliography}

[1] Astin JA, Soeken K, Sierpina VS, Clarridge BR (2006). "Barriers to the integration of psychosocial factors in medicine: Results of a national survey of physicians". J AmBoard Fam Med. Vol.19(6), pp. 557-65.

[2] Atulkar.S;\& Kesari.B.(2016). "Shopping Of Hypermarket Shoppers On Weekends". Indian Journal Of Marketing,Volume 46(11), pp. $36-49$.

[3] Balaji, Vedha \& Injodey, Joseph. (2017). Organic Food Products: A Study on Perceptions of Indian Consumers, Indian Journal of Marketing, pp. 47-26 10.17010/ijom/v47/il/108808.

[4] Bodeker G (2001). “Lessons on integration from the developing world's experience”. BMJ 322, pp. 164-7.

[5] Braz J Med Biol Res, RibeirãoPreto (2000). "Efficacy, safety, quality control, marketing and regulatory guidelines for herbal medicines (phytotherapeutic agents)". Brazilian Journal of Medical and Biological Research, Vol. 33(2), pp. 179-189.

[6] Chaitor Poyearleng, Zhao Kai, Saleh Shahriar, Ouaimon Payang Slim Reakine (2019). Factors Influencing Consumers' Purchasing Behavior on Organic Vegetables: A Case Study in Vientiane, Lao PDR. Open Journal of Social Sciences, Vol. 7 (2).

[7] Chakraborty, Chiranjivi (2016), "Babas join queue to ape Patanjali: Sri draws plan to fire up FMCG”, ET Bureau.

[8] Cheah, I., \& Phau, I. (2011). "Attitudes towards environmentally friendly products: The influence of eco-literacy, interpersonal influence and value orientation". Marketing Intelligence \& Planning, Vol. 29(5), pp. 452-472 